\title{
O perfil do financiamento dos partidos brasileiros (2006-2012): \\ o que as tipologias dizem?
}

The political reform agenda in Brazil:

what do typologies say?

Nas análises sobre as organizações partidárias, um elemento central de diferenciação das tipologias construídas é a relação e as conexões que as agremiações estabelecem com o Estado e a sociedade. Essa dimensão fornece subsídios fundamentais para entender a dinâmica de funcionamento organizacional, além de apresentar uma radiografia dos processos de adaptação e alteração dos modelos partidários inseridos em ambientes históricos e contextuais distintos.

No atual contexto partidário das democracias há um constante debate se as organizações partidárias ainda fundamentam sua principal razão de existência: a representação política. Em que pesem as inúmeras formas de se compreender o conceito de representação, é fato, apontado pela maior parte da literatura internacional, que os partidos políticos foram se transformando ao longo do século XX e início do século XXI. Não raro, análises políticas ainda tomam por base um sentimento nostálgico, procurando sustentar uma perspectiva de partidos políticos que possuem características similares aos partidos de massa (Duverger, 1970). Nesse ponto, é importante reconhecer

É professora associada da Universidade Federal do Rio Grande do Sul (UFRGS).E-mail: <krausesilvana@ yahoo.com.br>.

** É doutor em Ciência Política pela Universidade Federal do Rio Grande do Sul (UFRGS). E-mail: <mmrebello@yahoo.com.br>.

*** É doutorando em Ciência Política na Universidade de Brasília (UnB). E-mail: <josimar.cs@hotmail.com>. Agradecemos os comentários dos pareceristas anônimos da RBCP, os quais foram de enorme valia para o aprimoramento deste artigo. 
que são poucos os sistemas partidários que permanecem estáveis em sua relação com o Estado e a sociedade (Katz e Mair, 1997).

Em um esforço para averiguar o caso brasileiro, este artigo analisa especificamente uma dimensão importante da vida partidária: seu financiamento. A sobrevivência de qualquer organização partidária passa, necessariamente, por sua forma de financiar suas atividades, inclusive seu próprio fortalecimento para as eleições. Desse modo, avaliar como se sustenta a lógica do financiamento das atividades partidárias permite identificar indicadores para a construção de um diagnóstico a respeito das tendências e desafios que as legendas têm vivenciado nas democracias contemporâneas.

Pretendemos avaliar comparativamente a constituição do financiamento dos principais partidos brasileiros, com a intenção de detectar perfis e contrapor com modelos tipológicos que sustentam o debate sobre a dinâmica das organizações. Faz-se necessário destacar que nossa proposta é observar somente uma dimensão das diferentes tipologias destacadas na análise da ciência política. Nesse sentido, o objetivo principal é apresentar elementos empíricos que contraponham e forneçam sustentação ao debate teórico. Reconhecemos que as tipologias são constructus, elaborados para analisar o fenômeno em questão. Servem como “tipos ideais", ou seja, são aproximações de uma dinâmica que apresenta perfis seguidamente não encontrados, híbridos e/ou contrapostos aos modelos ideais.

Diferente de outros trabalhos que analisam o financiamento de campanhas, nossa preocupação reside em uma análise específica da estrutura financiadora da organização partidária: doação de pessoas jurídicas e pessoas físicas, contribuição dos próprios parlamentares e fundo partidário. Algumas investigações que procuram analisar os impactos do subsídio partidário sobre a competição e o congelamento (cartelização) do sistema partidário europeu já foram feitas por Scarrow (2006). Em geral, a ciência política brasileira tem deixado lacunas sobre como o financiamento estatal, por meio do fundo partidário, tem impactado o sistema partidário, especialmente em sua competitividade. Esta investigação visa contribuir para superação dessa lacuna.

$\mathrm{O}$ artigo está dividido em quatro partes. Primeiramente são analisados os principais modelos partidários sob o olhar dos clássicos, e, mais especificamente, as formas de financiamento apresentadas nas tipologias partidárias. A segunda parte delineia a formatação das regras do financiamento partidário no Brasil desde a Constituição de 1988 - fundamental para a compreensão 
do jogo pela busca de recursos. Seguimos então para a análise empírica, identificado as fontes de financiamento das principais legendas do país. Por último, contrapomos os modelos partidários clássicos com o perfil de financiamento dos partidos brasileiros, mostrando como alguns modelos se aproximam desse perfil e outros se afastam.

\section{Tipologias partidárias e financiamento organizacional}

A ciência política tem se dedicado à tarefa de elaborar tipologias partidárias (Gunther e Diamond, 2003; Safran, 2009). Na literatura especializada, as referências se fundamentam na raiz de quatros tipos ideais clássicos: partido de quadros, partido de massa, partido catch-all e partido cartel.

Trabalho pioneiro na designação de tipologias partidárias realizado por Duverger (1970) utiliza a expressão partido de quadros, partidos constituídos fundamentalmente por grupos parlamentares. Em relação à organização dessa tipologia, o vínculo dos adeptos desses partidos é tênue e sua base social não é ampla. Nesse tipo partidário, os principais membros são formados por "notáveis", pessoas ilustres, e tal característica é essencial para o perfil do financiamento da legenda. Os "notáveis" detêm boa penetração nos setores privados, como bancos e indústrias, que financiam as atividades partidárias através de doações. Considerando o momento em que Duverger analisa o partido de quadros em sua gênese, nas democracias ainda não consideradas de "massas", o mercado eleitoral era restrito (regime censitário), a manutenção da máquina partidária possui baixo custo financeiro e os recursos são exclusivamente financiados pelas elites econômicas (Duverger, 1970, p. 103), com as quais o partido de quadros mantém estreita ligação, pois esta é sua base social.

Com a ampliação do sufrágio, a estrutura dos partidos foi alterada, surgindo a formação clássica dos partidos de massa. Diferente do perfil anterior, as organizações de massa ampliaram de forma expressiva a participação da população como membros dos partidos, os militantes, que são mais ativos que eleitores ou simpatizantes. Nesse perfil, a principal fonte de financiamento advém dos seus filiados, gerando independência das legendas em relação aos grandes financiadores. O grau de comprometimento do membro do partido de massa é central para sua sobrevivência organizacional; aliás, um elemento definidor do partido de massa é ser financiado quase exclusivamente por seus militantes. A contribuição, por mais modesta que seja, engendra uma conexão estreita do indivíduo com a organização. Em 
alguns casos, a contribuição financeira não advém somente do membro do partido, mas de recursos sindicais. Uma característica que desponta nessa tipologia é a desconcentração e fragmentação da origem dos recursos, cujo efeito, em geral, é promover maior independência da legenda em relação a financiadores específicos, dado que o financiamento vem de diversos doadores com valores modestos (Duverger, 1970).

O desenvolvimento das democracias de massa após a Segunda Guerra Mundial configurou novos desafios. A diversificação e heterogeneização do eleitorado trouxeram mudanças significativas que impactaram diretamente a vida dos partidos, tanto do ponto de vista organizacional como de sua relação com os eleitores. A fluidez e o aumento da competição do mercado eleitoral criaram a necessidade de as organizações ampliarem o seu espectro de eleitores, suavizando um discurso classista, especialmente identificado com os partidos de massa. A ênfase não estava mais em obter somente o voto de grupos sociais específicos, como proletários, burgueses, católicos, protestantes, mas em conquistar o maior número de eleitores possíveis. Começava a era dos catch-all parties, termo cunhado pela primeira vez por Otto Kirchheimer (1966).

Fruto de produto histórico de um eleitorado mais secular, mutável e consumidor em massa, o catch-all pressiona antigos partidos classistas e de quadros a redimensionar suas estratégias organizacionais. Os partidos catch-all apresentam alterações de perfil percebidas por Kirchheimer (1966, p. 190): (a) drástica redução do conteúdo ideológico dos partidos; com a ampliação do leque eleitoral das legendas, o discurso dos líderes das organizações torna-se mais difuso e genérico na medida em que não se dirige a uma classe ou grupo específico; (b) fortalecimento das lideranças, uma vez que estas são julgadas mais pelo grau de eficiência do que avaliadas internamente em relação às metas organizacionais por correligionários, ou seja, os líderes ganham autonomia; (c) queda do papel do militante, do membro individual, uma vez que este não é o ponto central das campanhas; (d) redirecionamento da ênfase para largos setores sociais em detrimento da antiga classe gardée, afastando-se o partido de clientelas antigas; (e) acesso assegurado a uma ampla gama de grupos de interesse, ganhando, com isso, diversificação de financiamento eleitoral.

Kirchheimer (1966) admite que, nas organizações de massa, já existiam grupos de interesse, como os sindicatos e as associações profissionais. Todavia, a relação entre os grupos de interesse nessa tipologia partidária 
modifica-se completamente. Ambos adquirem gradativa autonomia e a relação torna-se muito mais uma troca de serviços. O efeito é que tanto a organização partidária como o grupo de interesse nunca devem apostar somente em um mesmo e único nicho. Um grupo de interesse, por exemplo, não financia apenas uma legenda esperando sua vitória, mas financia várias organizações para que possa influenciar na aplicação de políticas públicas independentemente do ganhador. No que diz respeito ao perfil de financiamento há mudanças fundamentais nessa nova tipologia. Uma associação patronal não doaria dinheiro a um partido socialista; em uma organização catch-all, associações que em princípio são vinculadas a setores conservadores podem doar para vários partidos de matrizes ideológicas diversas. Na essência do partido catch-all permanece um vínculo entre a sociedade, mas a relação do eleitor com a organização é volátil e gelatinosa. A fragilização diante da competição eleitoral faz a organização potencializar a diversificação das fontes financiadoras, criando relações tênues com os grupos de interesse.

Panebianco (2005, p. 513), dialogando com Kirchheimer, destaca a profissionalização dos partidos políticos.

No partido de massa descrito por Weber, Michels e por Duverger, um papel fundamental é exercido pelo "aparato" da burocracia de partido (aquela que define como "burocracia representativa"): a burocracia representativa é o instrumento por meio do qual os líderes do partido de massa mantêm ligações estreitas com os filiados e, mediante os filiados, com o grupo social de referência, a classe gardée. Já os profissionais desempenham um papel cada vez mais central no novo partido (os "especialistas", os técnicos dotados de conhecimentos especializados), muito úteis quando a organização desloca o seu centro de gravidade dos filiados para os eleitores.

Destarte, o autor indica certas diferenças entre o modelo burocrático de massa e o profissional eleitoral. No que diz respeito ao financiamento, Panebianco (2005, p. 514) observa que este se dá através de grupos de interesse e de fundos públicos. Tal perspectiva tem sido destacada na avaliação das tendências contemporâneas das organizações partidárias: a preponderância do uso do Estado para sobrevivência organizacional (Mair, 1994; Katz e Mair, 1997; Van Biezen e Kopecký, 2007).

Katz e Mair (1997) trazem uma contribuição seminal ao debate sobre a relação das organizações partidárias com o Estado. Os autores partem da 
análise de que o desenvolvimento partidário envolve três dimensões: sociedade civil, os próprios partidos e o Estado. Nos partidos considerados de massa, por exemplo, a organização é uma ponte entre Estado e sociedade civil, representando e mobilizando grande parte da população agora incluída pela ampliação do sufrágio. Na formatação do catch-all, há certo distanciamento com interesses organizados da sociedade civil, fazendo que o vínculo entre as organizações e os eleitores se torne mais tênue.

No último tipo de organização percebida (os autores não afirmam que outras novas tipologias organizacionais não possam ser construídas no processo de desenvolvimento das democracias contemporâneas), os partidos não estabelecem uma ligação com a sociedade civil e se conectam de forma sistemática com o Estado. Os autores incorporaram o Estado como variável fundamental para a compreensão da lógica de funcionamento das organizações partidárias contemporâneas. De fato, há elementos que indicam uma aproximação partidária com o Estado e uma clara tendência de distanciamento da sociedade civil (Mair, 1994, p. 10).

A crescente regulamentação do Estado nas várias dimensões da vida partidária torna pouco flexível o convívio da organização com a dinâmica da sociedade. Por um lado há como consequência um engessamento organizacional, dificultando a legenda desenvolver procedimentos que possibilitem uma adaptação às mutabilidades do ambiente. Por outro, as organizações constituem-se em reféns de uma ordem alheia, fazendo que sua existência dependa cada vez menos da competição do mercado eleitoral, e mais da máquina do Estado.

Segundo os autores houve também crescimento de pessoal trabalhando para os partidos, bem como aumento substancial de recursos financeiros das organizações partidárias. Muitos desses recursos seriam de subvenções estatais: em países como Finlândia, Noruega e Suécia, o total de recursos advindos do Estado superou o total de receitas advindas de outras fontes (Mair, 1994, p. 9).

A terminologia, importada da ciência econômica e utilizada para compreender o fenômeno, seriam os chamados partidos cartéis ${ }^{2}$. A compreensão ti-

Cartel compreendido como um pacto de união com fins de construção de oligopólio para restringir a competição (Blyth e Katz, 2005, p. 38). Em um mercado altamente competitivo os atores adotam uma estratégia de proteção diante das incertezas do mercado. O "pacto" cria uma proteção aos atores que estão nesse jogo competitivo, dificultando a entrada de novos. 
pológica partido cartel está baseada em uma perspectiva sistêmico-relacional. O partido cartel é definido especialmente no perfil de relação competitiva e modus operandi que a organização estabelece e manifesta no sistema partidário, dado que "cartel" é basicamente um modelo de ação e comportamento fundamentado na relação entre atores (Mair, 2003).

Nessa tipologia, as organizações estão inseridas em um sistema de competição limitado, ou, em outras palavras, gerenciado. A não competição de algumas agremiações para alguns cargos, por exemplo, é fruto de um cálculo que envolve o cartel, no qual um partido deixa de participar de uma eleição para obter benefícios como acesso ao espólio estatal, por exemplo. Desse modo, o processo de cartelização, se bem sucedido, inibiria a entrada de novos partidos políticos na arena parlamentar e congelaria o processo competitivo do sistema partidário (Van Biezen e Rashkova, 2011: 14).

Uma diferenciação fundamental entre o catch-all e o cartel seria o perfil da forma de financiamento partidário. Ao invés de a organização depender de uma variedade de fontes, centra-se substancialmente em subvenções estatais. Podemos perceber, então, que o financiamento partidário do partido cartel depende excessivamente do Estado, ao contrário do catch-all, cujos recursos financeiros advêm de várias fontes, a grande maioria de grupos de interesse.

É frequentemente real ou potencial o acesso a cargos públicos como forma de os partidos acumularem recursos organizacionais tais como pessoal e dinheiro. Nesse sentido, o Estado, comumente fornecedor desses recursos, torna-se um meio pelo qual os partidos podem assegurar sua continuidade e sobrevivência (Mair, 1994, p. 7; tradução livre dos autores).

Desde sua gênese, os partidos modernos configuraram-se de modos distintos. Variáveis históricas, institucionais e culturais impactaram sua formação, produzindo constituições e dinâmicas diversas ao longo da vida das organizações. As tipologias são referenciais e constructos que orientam e fornecem parâmetros para a análise da dinâmica organizacional, permitindo perspectivas comparativas. São tipos ideais não encontrados na sua forma "pura". Nesse sentido, possibilitam, aos estudos de natureza empírica, diagnósticos de tendências. O Quadro 1 mostra as tipologias em relação ao financiamento partidário. 
Quadro 1 - Tipologias em relação ao financiamento partidário

\begin{tabular}{c|c|c|c|c}
\hline modelo partidário & quadros & massa & catch-all & Cartel \\
\hline $\begin{array}{c}\text { dependência de re- } \\
\text { cursos financeiros em } \\
\text { relação à sobrevivência } \\
\text { organizacional }\end{array}$ & baixa & média & Alta & Alta \\
\hline $\begin{array}{c}\text { principal fonte finan- } \\
\text { ciadora }\end{array}$ & $\begin{array}{c}\text { grupos financei- } \\
\text { ros/industriais e } \\
\text { comerciantes }\end{array}$ & $\begin{array}{c}\text { membros do } \\
\text { próprio partido }\end{array}$ & $\begin{array}{c}\text { grupos de interesse } \\
\text { variados; ex.: } \\
\text { empresas, sindi- } \\
\text { catos, associações } \\
\text { comerciais }\end{array}$ & $\begin{array}{c}\text { subsídio estatal; } \\
\text { ex: fundos pú- } \\
\text { blicos e espólio } \\
\text { estatal, como } \\
\text { cargos }\end{array}$ \\
\hline
\end{tabular}

Fonte: Elaboração dos autores com base em Duverger (1970), Kirchheimer (1966), Panebianco (2005) e Katz e Mair (1997).

No primeiro tipo descrito por Duverger (o partido de quadros), a necessidade de recursos é mais baixa pela pouca competitividade eleitoral em um regime censitário. No partido de massa, também descrito por Duverger, a dependência de recursos aumenta, porém, devido à atividade militante, o trabalho desenvolvido pelo membro para o partido atenua a necessidade de dinheiro, além disso, a contribuição advém deste mesmo militante.

No terceiro tipo partidário, o catch-all, as fontes financiadoras são as mais diversas possíveis, no qual a eleição para um cargo eleva o agente político à condição de servidor de interesses de vários grupos. Para o partido, é necessário maior aporte de recursos em função da queda do papel dos militantes e a necessidade de especialistas e marqueteiros em eleições. Da parte de grupos empresariais, a doação dá-se para inúmeras organizações, inclusive as de matriz ideológica mais à esquerda.

Quanto ao partido cartel, o Estado torna-se a principal fonte de recursos de sobrevivência organizacional. Tal condição não torna mais barata a competição política. Como vimos no Quadro 1, optamos por desconsiderar o fator cronológico, uma vez que entendemos que tipos ideais partidários podem coexistir em épocas distintas (Wolinetz, 2002).

Na verdade, como sugere Wolinetz (2002, p. 162) seria mais adequado falarmos na coexistência de distintas tipologias partidárias em um mesmo momento histórico, convivendo simultaneamente, alguns desses partidos buscando cargos, outros políticas e outros votos. É preciso também reco- 
nhecer a possibilidade de configurações partidárias “ mix", apresentando alta variação tanto em sua estrutura organizacional interna como na maneira pela qual se relacionam com o Estado e a sociedade.

\section{As regras do financiamento partidário na nova democracia brasileira}

As regras de financiamento dos partidos estabelecem um ordenamento central na ação das organizações. Tais regras não são somente variáveis importantes que delineiam e fundamentam os espaços e a formatação do jogo competitivo em que as legendas estão inseridas, mas também configuram estratégias que impactam na dinâmica interna das organizações.

Com a nova Constituição, de 1988, do regime civil democrático, os partidos adquiriram ampla liberdade e autonomia organizativa e de funcionamento interno (Artigo $17 \$ 1^{\circ}$ ). No que diz respeito às formas de financiamento, ela proibiu as legendas de receberem recursos estrangeiros, estabeleceu a obrigação de prestação de contas à Justiça Eleitoral, previu o uso de um fundo partidário e ainda estabeleceu o direito ao acesso gratuito de rádio e TV. As organizações partidárias foram consideradas instituições jurídicas e registradas com seus estatutos no Tribunal Superior Eleitoral (Artigo 17).

A primeira eleição direta para presidência do país, em 1989, trouxe uma experiência amarga, levando inclusive ao impeachment em 1992 do presidente eleito. No centro do problema estava justamente a corrupção devido às contribuições ilegais e tráfico de influência entre doadores, partido e governo. A reação foi a criação de uma lei temporária (Lei ${ }^{\circ}$ $8.713 / 1993)$ para regulamentar o pleito de 1994. A novidade é que esta legislação expressou de forma nítida a maneira dos partidos administrarem suas finanças durante as campanhas políticas e, também, como poderiam utilizar seus recursos advindos de empresas privadas, doações de pessoas e do fundo partidário. Dessa forma, foi permitido às empresas financiar partidos, mas com limites estabelecidos. Para gastos acima do limite estabelecido, a lei previa punição com pena de detenção e multa. Um aspecto dessa legislação, muito criticada, foi que ela deveria ter sido mais rígida quanto às formas de financiamento privado. A lei estabelece que $10 \%$ dos rendimentos brutos anuais de uma pessoa física e $2 \%$ da receita bruta de uma pessoa jurídica podem ser doados a uma legenda. Há aqui 
dois problemas importantes para o caso brasileiro. O primeiro é que ela trata de percentuais e não valores. Com isso, os grupos empresariais ou pessoas físicas com alta rentabilidade podem fornecer um valor de doação bem maior. Isso traz efeitos diretos nas possibilidades de influência de grandes grupos econômicos não somente no processo político eleitoral, mas na vida interna do partido. A segunda questão problemática é que a cultura brasileira é muito criativa. O fato de uma pessoa física ou jurídica ter limites de percentuais na contribuição não impede que grandes grupos econômicos tenham formalmente mais do que uma pessoa jurídica registrada. Isso também acontece com pessoas físicas, que podem usar outros nomes de parentes e amigos para fornecer financiamento de campanhas. Além disso, devemos considerar que não há limites de gastos em campanhas, ou seja, cada candidato pode gastar o que achar necessário, desde que comprove a origem e respeite os princípios estabelecidos.

No ano de 1997, prevendo a eleição de 1998, foi votada uma lei permanente (Lei $\mathrm{n}^{\circ}$ 9.504) que basicamente mantém os princípios da anterior (Lei no 8.713/1993). De fato, ela consolidou o papel da Justiça Eleitoral na fiscalização dos gastos dos partidos, dando à instituição poderes claros para tomar as devidas providências. Essa lei, além de proibir doações já estipuladas na Constituição, explicitou de forma clara a proibição dos partidos e candidatos de receberem verbas de concessionários ou permissionários de serviços públicos ou de organizações não governamentais que recebem recursos públicos. A intenção é justamente não permitir o abuso de influência de empresas que têm uma relação estreita com a máquina do Estado e com governos.

A “Lei dos Partidos Políticos" (Lei no 9.096/1995), que regulou as formas de financiamento e contabilidade dos partidos, continuou possibilitando a doação de empresas privadas, e manteve a proibição de doações de entidades de classe, instituições estrangeiras e de governo. Essa lei também reformulou o fundo partidário. Foram estabelecidos critérios para as dotações advindas do orçamento como também de distribuição dos recursos aos partidos. A importância do fundo partidário pode ser percebida no Gráfico 1 pela evolução dos valores despendidos a partir da implementação da "Lei dos Partidos Políticos". 
Gráfico 1: Evolução do Fundo Partidário

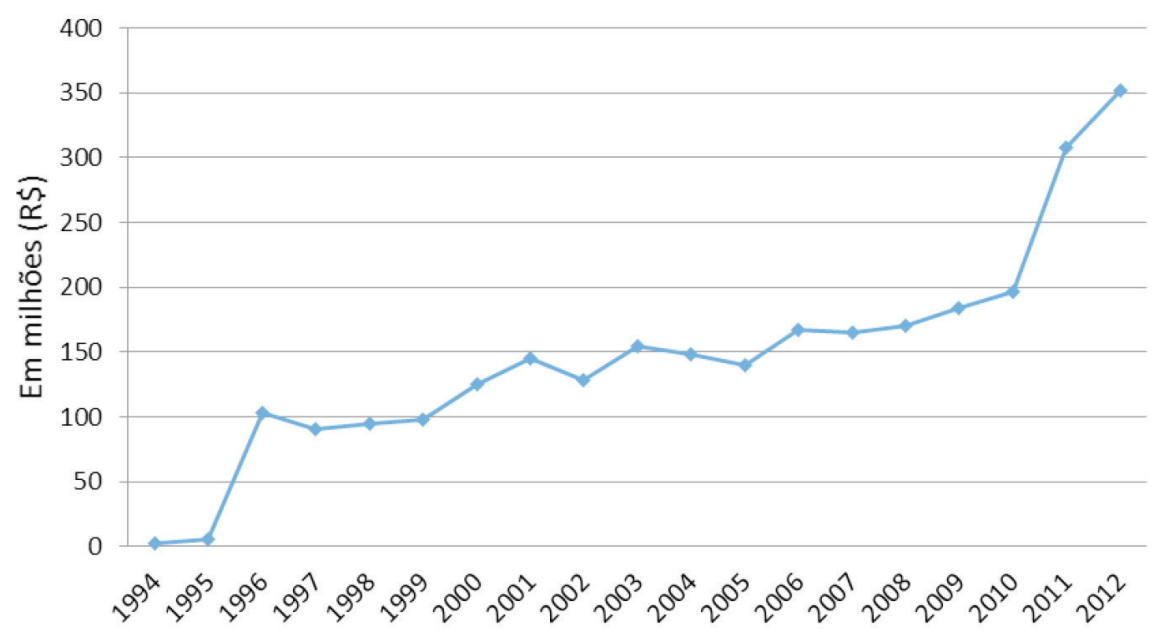

Fonte: Dados elaborados por Ribeiro (2009) e dados brutos do TSE, disponíveis em: < http://www.tse.jus.br/transparencia/relatorio-cnj/fundo-partidario > 0 gráfico traz os montantes totais repassados aos partidos, somando-se os duodécimos da dotação orçamentária e as multas aplicadas pela Justiça Eleitoral.

O recurso do Fundo Partidário a partir da "Lei dos Partidos Políticos" advém de quatro fontes:

a) multas e penalidades baseadas no Código Eleitoral de 1950;

b) recursos financeiros destinados por lei;

c) doações de pessoas físicas ou jurídicas ao Fundo;

d) dotações do orçamento da União.

Apesar de os partidos terem ampla liberdade para gerir esses recursos, eles são obrigados a destinar $20 \%$ do total da verba recebida para suas fundações, aplicando em pesquisa e educação política. A lei previa mudanças gradativas nos critérios para os partidos se adaptarem. A expectativa era de que, ao final dessa fase, as legendas com maior representação fossem privilegiadas.

Antes da "Lei dos Partidos Políticos" de 1995, a proporção de distribuição do fundo partidário era $20 \%$ dos recursos distribuídos para todos os partidos, independentemente da força eleitoral e o restante de acordo com a 
representação parlamentar (Câmara dos Deputados) $)^{3}$. A nova lei estabelecia que, ao final da fase de adaptação, a distribuição seria de apenas $1 \%$ do total do fundo para todos os partidos e o restante deveria ser dividido entre as legendas que cumprissem os requisitos mínimos de representação: $5 \%$ de votos válidos ao menos em $1 / 3$ dos estados e $2 \%$ nos demais estados ${ }^{4}$. Essa regra deveria ser aplicada a partir dos resultados eleitorais de 2006, mas a reação dos pequenos partidos foi intensa e o Supremo Tribunal Federal considerou inconstitucional uma série de aspectos. Durante a fase de transição (1995 até 2006), houve uma longa instabilidade jurídica e disputa quanto aos critérios da distribuição dos recursos, e seguidas mudanças na aplicação da lei.

Em 2007 foi finalmente aprovada a Lei $n^{\circ} 11.459$ e sancionada pelo Presidente Lula. Essa lei estabeleceu um critério menos concentrador de distribuição do fundo partidário do que previa a "Lei dos Partidos Políticos". Ficou assim estabelecido que 5\% dos recursos passam a ser distribuídos a todos os partidos que tenham registro no Tribunal Superior Eleitoral e 95\% são distribuídos de acordo com a votação das legendas ${ }^{5}$.

Os recursos do fundo partidário são repassados pela Justiça Eleitoral diretamente para os diretórios nacionais das legendas. Isso acaba incentivando uma concentração de poder dentro das organizações, pois com a autonomia organizativa das legendas, adquirida pela Constituição de 1988, elas decidem como irão redistribuir esses recursos. Em um país do tamanho do Brasil, isso é fundamental, pois os diretórios municipais e regionais ficam assim dependendo muito das lideranças que estão no centro do poder nacional do partido.

No caso da nova democracia brasileira, são então permitidas três fontes de financiamento pela legislação: fundo partidário, recursos próprios e doações de pessoas jurídicas ou físicas (Lei no 9.504/1997, Artigo 20). A seguir, apresentamos um quadro comparativo (Quadro 2), que elucida cronologicamente as principais normas que regulamentam o financiamento partidário.

Assim foi durante três décadas: 1970, 1980 e 1990.

O Brasil tem um sistema federativo com 26 estados mais o Distrito Federal.

Esse critério é diferente do percentual de representação na Câmara dos Deputados. Para o Brasil, é importante, pois muitos partidos têm força eleitoral concentrada em algumas unidades da federação. Há também um debate corrente sobre a forma do cálculo da representação dos estados na Câmara dos Deputados, pois alguns deles se consideram prejudicados. 
Quadro 2 - Normas que regulamentam o financiamento partidário

\begin{tabular}{|c|c|}
\hline Lei & Norma \\
\hline $\begin{array}{l}\text { Constituição de } \\
1988 \text { Art.17 } \\
\end{array}$ & $\begin{array}{l}\text { Liberdade das organizações partidárias. Autonomia } \\
\text { organizativa e de funcionamento interno. }\end{array}$ \\
\hline Lei n 8.713/93 & $\begin{array}{l}\text { Temporária para o pleito de 1994. Regulamentou a administração e utilização } \\
\text { das finanças dos partidos em campanhas políticas. Permitiu às empresas } \\
\text { financiar partidos, mas com limites estabelecidos. }\end{array}$ \\
\hline $\begin{array}{l}\text { Lei dos Partidos } \\
\text { Políticos (Lei no } \\
9.096 / 95)\end{array}$ & $\begin{array}{l}\text { Regulou as formas de financiamento e contabilidade dos partidos e reformulou } \\
\text { o fundo partidário. Criou critérios para as dotações advindas do orçamento } \\
\text { e distribuiç̧ão dos recursos aos partidos. }\end{array}$ \\
\hline Lei n 9.504/97 & $\begin{array}{l}\text { Manteve os princípios da Lei nº 8.713/93. Consolidou o papel da Justiça Eleitoral } \\
\text { na fiscalização dos gastos dos partidos. Proibiu as doações já estipuladas na Constituição, } \\
\text { explicitou a proibição de partidos e candidatos de receberem verbas de concessionários } \\
\text { ou permissionários de serviços públicos ou de organizações não governamentais que } \\
\text { recebessem recursos públicos. Permitiu três fontes de financiamento: fundo partidário, } \\
\text { recursos próprios e doações de pessoas jurídicas ou físicas. }\end{array}$ \\
\hline $\begin{array}{l}\text { Lei } n^{0} \\
11.459 / 2007\end{array}$ & $\begin{array}{l}\text { Estabeleceu um critério menos concentrador de distribuição do fundo partidário } \\
\text { que a "Lei dos Partidos Políticos” (Lei n 9.096/95) previa. }\end{array}$ \\
\hline
\end{tabular}

Fonte: Elaboração dos autores.

\section{As fontes de financiamento: o predomínio da conexão institucional}

Os dados ${ }^{6}$ trabalhados foram informados pelo Tribunal Superior Eleitoral (TSE). Nos gráficos a seguir, temos um panorama específico das fontes dos recursos dos principais partidos de acordo com sua coloração ideológica ${ }^{7}$. A classificação ideológica partidária utilizada pela ciência política brasileira tem sido praticamente a mesma em vários estudos. Apesar de distintas metodologias empregadas (Marenco, 2001; Martins Rodrigues, 2002; Zucco, 2011; Tarouco e Madeira, 2013) o resultado do enquadramento dos partidos no espectro esquerda-centro-direita não tem apresentado nuances expressivas. O PPS, na verdade, é a sigla que vem apresentando um reposicionamento ideológico, sendo considerada de centro em análises mais recentes (Zucco, 2011). Em nosso artigo, tivemos como método utilizar um mapeamento da posição ideológica mais recorrente segundo a bibliografia consolidada, uma

6 Disponibilizados pela Coordenadoria de Exame de Contas Eleitorais e Partidárias (COEPA), vinculada à Secretaria de Controle Interno e Auditoria do TSE. Constituíram o material de análise as peças contábeis referentes aos exercícios de 2006, 2007, 2008, 2009, 2010, 2011 e 2012 dos dez partidos políticos. Os dados do ano de 2006 nos foram enviados em CD pelo TSE. Agradecemos a atenção de Jardel Vieira, do TSE, que nos auxiliou na compreensão das peças contábeis.

O critério básico consistiu em utilizar as principais referências bibliográficas da ciência política brasileira contemporânea, como feito pelo grupo de pesquisa Partidos e Coligações na Nova Democracia Brasileira (cf. Krause; Dantas e Miguel, 2010). 
discussão mais aprofundada pode ser encontrada em Krause, Dantas e Miguel (2010). Assim, consideramos direita o DEM, o PP, o PTB e o PR. No centro, colocamos PMDB e PSDB. Na esquerda, incluímos PDT, PSB, PPS e PT. Analisaremos, primeiramente, o bloco da direita, depois o bloco do centro e, por último, o bloco da esquerda. Selecionamos três partidos de cada linhagem ideológica, respectivamente DEM, PSDB e PT, conforme Gráficos 2, 3 e 4.

Quando analisamos o perfil de fontes de financiamento dos principais partidos de direita, o primeiro aspecto que chama atenção é a importância do fundo partidário para a vida desses partidos e as insignificantes contribuições e doações ${ }^{8}$ de pessoas físicas. Entre 2006 e 2012, os recursos de simpatizantes, militantes e parlamentares são praticamente inexistentes entre todas as organizações ${ }^{9}$.

Os dados não demonstram apenas que o fundo partidário é o grande financiador, mas que a diferença é muito significativa quando comparamos com o peso das outras modalidades. Em quase todos os anos analisados, mais de $70 \%$ dos recursos arrecadados pelas organizações provêm somente do fundo partidário. Verificamos uma forte dependência dos recursos públicos para essas organizações poderem financiar suas atividades cotidianas. Há apenas três situações isoladas em que o peso do fundo partidário é ultrapassado. As duas primeiras se referem ao DEM. Um dos principais partidos de oposição ao governo Lula, no ano das eleições municipais de 2008 apresentou vertiginoso crescimento de doações de organizações privadas; enquanto em 2007 não houve doações de empresas privadas, em 2008 o valor doado atingiu mais de R \$ 31 milhões. Em 2011, a legenda também não havia recebido nenhuma doação de pessoa jurídica privada; no ano seguinte ela recebeu R $\$ 22$ milhões. A terceira situação se refere ao Partido Progressista (PP), partido com raízes constituídas por lideranças associadas ao antigo regime civil-militar. Em 2009, o PP recebeu pouco mais de $\mathrm{R} \$ 1$ milhão e, no ano seguinte, a cifra ultrapassou a ordem de R 17 milhões. A proximidade da organização com o governo petista pode ser responsável por essa implosão de doações de grupos econômicos.

\footnotetext{
3 Para a prestação de contas ao TSE, "contribuições" são consideradas de filiados e "doações" de pessoas físicas não filiadas (simpatizantes). Neste artigo, consideramos essas fontes de recursos no cômputo de pessoas físicas, pois as diferenças não são significativas.

As doações dos parlamentares em todos os partidos (direita, centro e esquerda) são pouco significativas quando comparada com as outras modalidades. Isso se deve especialmente por duas questões. Uma porque o universo dos parlamentares é pequeno e, portanto, não tem muitas potencialidades. Outra é que a maioria dos partidos não estabelece em seus estatutos critérios e exigências de contribuições de seus políticos à legenda.
} 
O outro aspecto é a importância do perfil de financiamento de organizações jurídicas nas legendas. Destaca-se o comportamento das pessoas jurídicas em anos eleitorais $(2006,2008,2010,2012)$. Nesses anos, o percentual da arrecadação financeira de empresas privadas sobre o total dos recursos em relação aos anos eleitorais, cresceu em todas as siglas de direita. No caso dos Democratas, em 2006 o valor ficou em 28\%, em 2008, 62\%, em 2010, $17 \%$, e, em 2012, 64\%. No PP, a participação foi de $8 \%, 17 \%, 56 \%$ e $41 \%$ em 2006, 2008, 2010 e 2012, respectivamente. No PTB, a participação desse tipo de financiamento foi mais limitada, possivelmente por ser um partido menor, portanto com uma densidade eleitoral mais frágil. Os trabalhistas apresentaram 15\% em 2006, 10\% em 2008, 17\% em 2010 e $21 \%$ em 2012 . A última sigla de direita, o PR, teve apenas $0,1 \%$ de participação de doações de organizações privadas em 2006, 26\% em 2008, 5\% em 2010 e 1\% em 2012. Em todas as legendas, sem exceção, houve um movimento claro de aumento de investimento nesses períodos e diminuição em anos sem eleições (2007, 2009 e 2011). Em anos não eleitorais, por exemplo, nenhuma legenda alcançou $10 \%$ de recursos advindos do financiamento por pessoas jurídicas.

Gráfico 2: Perfil de financiamento dos Democratas (DEM)

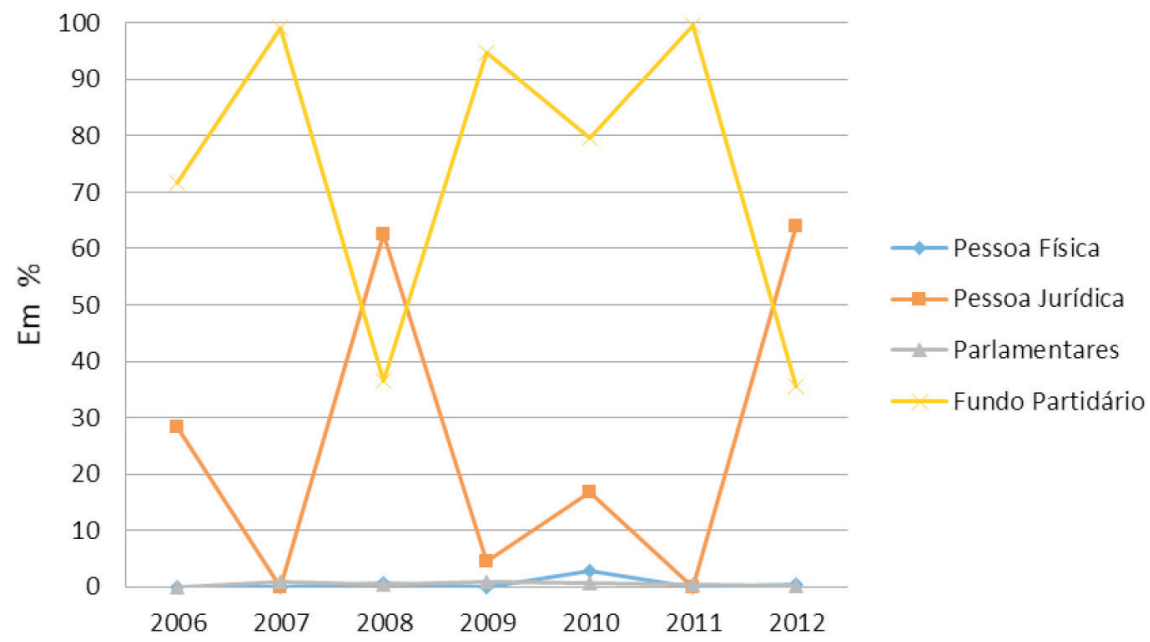

Valores (em milhões de reais): Pessoa física: $2006=0 ; 2007=0 ; 2008=332.400,01 ; 2009=0 ; 2010=750.000,01$; $2011=0 ; 2012=200.000,00$; Pessoa jurídica: $2006=8.660 .000,00 ; 2007=0 ; 2008=31.725 .270,25 ; 2009=952.870,23$; $2010=4.330 .000,00 ; 2011=0 ; 2012=39.547 .500,09 ;$ Parlamentares: $2006=11.660,00 ; 2007=150.660,00 ; 2008=$ $175.200,00 ; \quad 2009=169.500,00 ; \quad 2010=169.800,00 ; 2011=91.200,00 ; \quad 2012=76.800,00$; Fundo partidário: 
$2006=22.025 .344,98 ; \quad 2007=15.800 .832,20 ; 2008=18.578 .898,55 ; \quad 2009=20.093 .810,00 ; \quad 2010=20.699 .896,61$; $2011=23.057 .747,25 ; 2012=22.552 .984,09$. Fonte: Dados elaborados a partir das informações do TSE, disponíveis em: <http://www.tse.jus.br/partidos/contas-partidarias/prestacao-de-contas-partidarias>.

Os dois partidos brasileiros de centro apresentam um padrão muito semelhante aos de direita, quando observamos que o recurso público é quase sem exceção a maior fonte de arrecadação. Na maioria dos anos, mais de $80 \%$ do total de recursos provêm do fundo partidário. Nesses partidos, também é inexpressivo o peso de recursos vindos de cidadãos (pessoas físicas), sejam de militantes, simpatizantes ou parlamentares. No caso de doações de pessoas físicas, há uma pequena exceção no ano de 2010, no qual PMDB e PSDB arrecadaram mais de R 2 milhões e mais de R $\$ 12$ milhões, respectivamente. Ainda assim, a participação no montante arrecadado não atinge $10 \%$.

O PSDB, maior legenda de oposição ao governo Lula, apresentou um aumento vertiginoso de doações de organizações empresariais no ano das eleições municipais de 2008 e nacionais de 2010. Entre 2007 e 2008, a participação desse tipo de doações foi de $12 \%$ a 57\%. Já entre 2009 e 2010, o salto foi ainda maior, indo de $11 \%$ a $72 \%$. Isso indica novamente duas dimensões. A primeira, em 2008, o interesse de algumas organizações privadas em apoiar o partido em ano de disputas pelo poder local. A segunda, em 2010, a manifestação de alguns grupos privados em apoiar o partido da oposição. Interessante que, em 2011, o financiamento de empresas caiu vertiginosamente e se recuperou um pouco em 2012.

Mas o interesse de corporações privadas também foi significativo para o PMDB nas eleições de 2008 e 2010. O partido é uma das maiores legendas brasileiras e foi um suporte político fundamental para o governo do presidente Lula. Em 2007, não houve nenhuma doação de pessoa jurídica; no ano seguinte cerca de R 8 milhões foram doados, representando quase um quarto do valor total arrecadado pela agremiação naquele ano. Entre 2009 e 2010, o valor correspondente às doações de organizações privadas passou de R 300 mil para mais de R 3 milhões, com a participação desse tipo de financiamento subindo de $1 \%$ para $11 \%$.

O movimento averiguado nos partidos de direita, de um maior investimento de corporações em anos eleitorais (2006, 2008 e 2010, 2012) e diminuição em anos sem eleições (2007, 2009 e 2011), se repetiu nos partidos de centro, com uma única exceção em 2012, no caso do PMDB, no qual o volume desse tipo 
de arrecadação caiu entre 2011 e 2012. O partido, no ano de 2007, não recebeu doações de empresas e, em 2009 e 2011, sua participação não chegou a atingir $10 \%$. O PSDB apresentou uma queda abrupta dessa modalidade de doações em anos não eleitorais; a participação desse financiamento sobre o valor total correspondeu a $12 \%, 11 \%$ e $7 \%$ em 2007, 2009 e 2011, respectivamente.

Gráfico 3: Perfil de financiamento do Partido da Social Democracia Brasileira (PSDB)

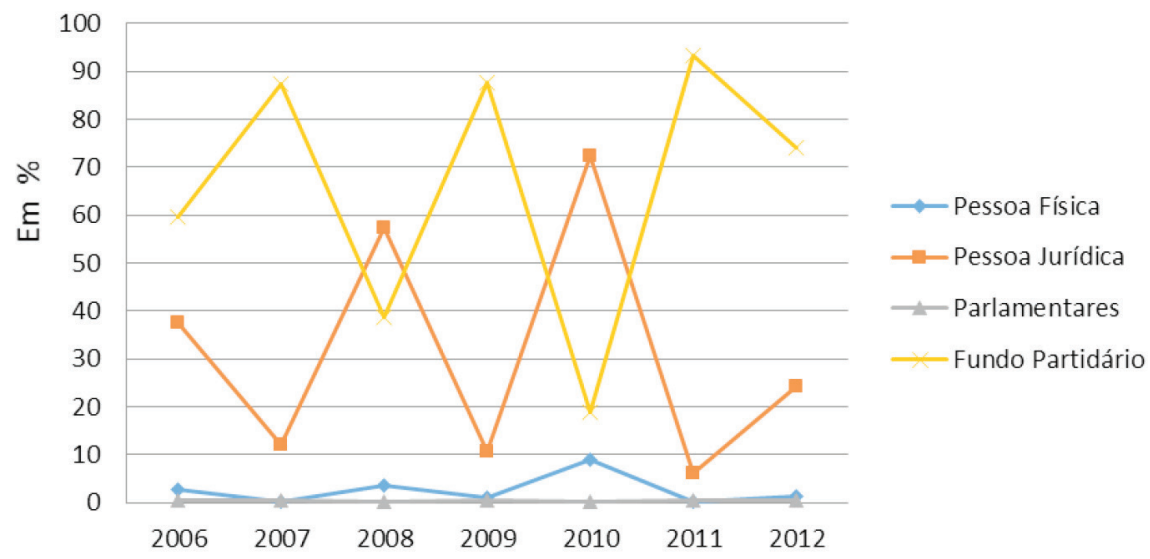

Valores (em milhões de reais): Pessoa física: $2006=1.002 .250,00 ; 2007=75.000,00 ; 2008=2.250 .000,00 ; 2009=$ 300.483,00; 2010=12.410.050,00; 2011 = 30.000,00; 2012=693.000,01; Pessoa jurídica: 2006=13.646.830,00; $2007=2.950 .000,00 ; \quad 2008=34.863 .400,00 ; \quad 2009=3.119 .643,05 ; \quad 2010=99.982 .155,56 ; \quad 2011=2.355 .000,00$; $2012=12.029 .650,00 ;$ Parlamentares: $2006=128.440,00 ; \quad 2007=140.180,00 ; \quad 2008=174.903,00 ; \quad 2009=$ $165.062,50 ; \quad 2010=151.859 .50 ; 2011=175.005,50 ; 2012=205.184,00$; Fundo partidário: $2006=21.695 .824,78$; $2007=21.490 .594,24 ; 2008=23.390 .701,70 ; 2009=25.319 .825,59 ; 2010=26.105 .917,36 ; 2011=35.863 .459,36$; 2012=36.711.012,89. Fonte: Dados elaborados a partir das informações do TSE, disponíveis em: <http://www.tse.jus. br/partidos/contas-partidarias/prestacao-de-contas-partidarias>.

O perfil do financiamento dos partidos de esquerda apresenta especialmente três questões interessantes. A primeira é a semelhança com relação aos outros partidos no que diz respeito à grande dependência do financiamento do fundo partidário, bem como a pequena contribuição e doação de pessoas físicas e de parlamentares. Esses dados indicam a relação frágil que os partidos de esquerda têm com a militância e simpatizantes. Com exceção do PSB em 2007 e do PPS em 2011, nenhum partido alcançou 5\% na participação da doação de pessoas físicas às legendas sobre o montante total arrecadado. Em alguns anos, essa participação é tão inexpressiva que 
não chega a $1 \%$ do valor total. Em valores absolutos, nenhum partido de esquerda somou sequer R \$ 1 milhão. Se esse recurso fosse o único possível de utilização pelas legendas, a manutenção da organização partidária, em um país do tamanho do Brasil, seria inviável. O modelo tradicional de partidos de massa, com militantes participando na vida partidária e contribuindo com a vida financeira da organização, foge do padrão encontrado, sem exceção.

Quanto à contribuição exclusiva dos parlamentares, o número é similar ao encontrado pelas doações de pessoas físicas. No PDT e no PSB, esses recursos são insignificantes, sendo sempre menores que 3\% da arrecadação total partidária. Já no caso do PT, embora tais recursos ainda sejam limitados quando comparados com o volume arrecadado pelo fundo partidário e doação de pessoas jurídicas, sua participação é maior do que no restante do sistema partidário, indo de 3,5\% em 2006 e atingindo seu pico em 2012, com $8 \%$. O PPS tem oscilações quanto a esse tipo de financiamento. Em 2006, 10\% do valor total arrecado tem como fonte os parlamentares; já no ano seguinte, essa participação é inferior a $1 \%$.

A segunda questão interessante diz respeito ao movimento observado nos partidos de direita e de centro de quedas nos recursos de pessoas jurídicas em anos sem eleição e crescimento quando ocorrem os pleitos. Nas organizações de esquerda, essa distinção não se apresenta de forma tão nítida ou significativamente diferenciada, com exceção o PT. No caso do PDT, a contribuição de pessoas jurídicas era insignificante até 2010, quando o valor aumentou de R 150 mil para R 8 milhões. O perfil atinge, em 2011, impressionantes $\mathrm{R} \$ 80$ milhões para, em 2012, cair a R $\$ 14$ milhões. O PSB apresenta um comportamento mais próximo das legendas de centro e de direita, com alguma participação desse financiamento em anos eleitorais: 26\% (2006), 52\% (2008), 8\% (2010) e 16\% (2012), ao passo que, em 2007, 2009 e 2011, não houve doações de pessoas jurídicas. Quanto ao PPS, em 2008 e em 2012, há um ingresso de doações de empresas privadas relevante, atingindo cerca de um quarto do montante arrecadado pelo partido naqueles anos. Aliás, as doações de empresas privadas no ano de eleições locais são altas, evidenciado que é importante para as empresas financiar os partidos políticos a fim de que interesses locais sejam perseguidos.

Por fim, é a dissonância do PT, certamente advinda da posição do partido no governo. Observa-se que, especialmente nos anos eleitorais de 2006, 
2008 e 2010, houve maior financiamento de organizações empresariais, superando a receita recebida do fundo partidário. Em 2006, a participação do financiamento por empresas privadas é de 57\%; em 2008, de 68\%; e em 2010, de 57\% novamente. Somente em 2012, tal participação foi menor: $37 \%$. O PT, ao longo dos anos de 2006 a 2012, arrecadou mais de R 225 milhões em doações de pessoas jurídicas, sendo a legenda que mais ganhou dinheiro com esse tipo de financiamento no período. Mesmo em anos não eleitorais, o valor arrecadado pela organização foi expressivo, tendo uma participação sempre superior a $24 \%$ do total dos recursos arrecadados; tal característica só foi encontrada no PT. Fica visível o quanto o Partido dos Trabalhadores não possui um perfil próximo aos partidos de massa quanto ao financiamento, sendo a contribuição de militantes e simpatizantes ínfimas quando comparadas com as doações de pessoas jurídicas e o fundo partidário.

Gráfico 4: Perfil de financiamento do Partido dos Trabalhadores (PT)

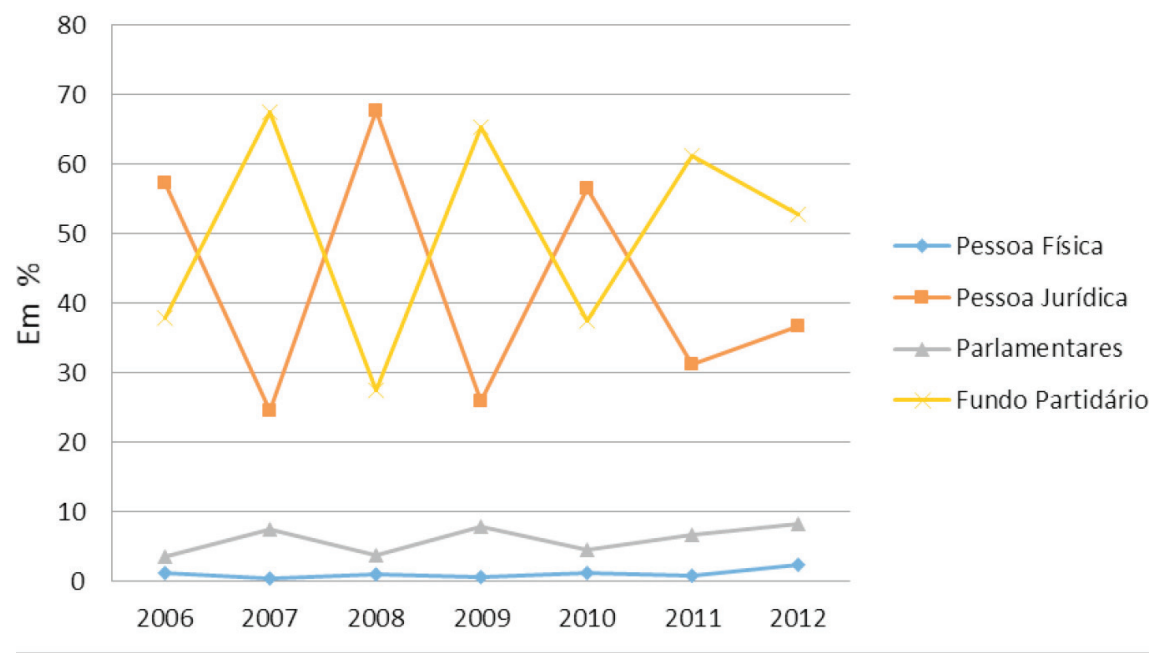

Valores(emmilhõesdereais):Pessoafísica:2006 $=944.679,07 ; 2007=149.208,61 ; 2008=848.500 .19 ; 2009=302.783,63$; $2010=989.927,68 ; 2011=748.729,66 ; 2012=2.326 .744,40 ;$ Pessoa jurídica: $2006=42.239 .153,10 ; 2007=8.703 .901,00$; $2008=60.270 .535,72 ; 2009=10.882 .924,19 ; 2010=42.780 .424,88 ; 2011=26.269,950 ; 2012=35.112 .893,00 ;$ Parlamentares: $2006=2.580 .475,21 ; 2007=2.709 .145,21 ; 2008=3.296 .846,89 ; 2009=3.355 .897,00 ; 2010=3.534 .509,67$; $2011=5.655 .296,17 ; 2012=7.874 .185,89$; Fundo partidário: $2006=27.844 .833,76 ; 2007=23.995 .607,25 ; 2008=$ $25.383 .914,63 ; 2009=27.439 .497,48 ; 2010=28.301 .394,70 ; 2011=51.165 .935,51 ; 2012=52.824 .169,68$. Fonte: Dados elaborados a partir das informações do TSE, disponíveis em: <http://www.tse.jus.br/partidos/contas-partidarias/ prestaca0-de-contas-partidarias $>$. 


\section{Contrapondo com as tipologias}

A contraposição do perfil encontrado com as tipologias nos permite algumas conclusões. No entanto, é preciso ter clareza e parcimônia nas avaliações e reflexões dos achados. Como já destacado no início deste artigo, a dimensão específica tratada neste estudo, financiamento partidário, é apenas uma de outras que compõem os indicadores estabelecidos nos tipos ideais clássicos. É preciso também considerar variáveis centrais que impactam na formatação dos “tipos partidários". A legislação (eleitoral, partidária e de financiamento político), bem como o sistema eleitoral constituem fundamentos básicos sob os quais as organizações vão construindo seus alicerces e suas estratégias de sobrevivência. Queremos dizer com isso que o perfil encontrado de uma tipologia também reflete o arcabouço institucional em que os partidos estão inseridos, produzindo indicadores próximos ou distantes com uma ou outra tipologia. Além disso, os achados são de alcance limitado, pois se referem apenas ao caso brasileiro. É possível que as tendências detectadas não ocorram em outras democracias.

Encontramos evidências que os partidos analisados se distanciam claramente do modelo de financiamento das tipologias de partidos de quadros e de massa. No que diz respeito à caracterização do financiamento evidenciado no partido de quadros, as razões parecem ser mais óbvias. $\mathrm{O}$ contexto eleitoral altamente competitivo nas democracias contemporâneas não tornaria viável a sobrevivência organizacional com recursos advindos exclusivamente de notáveis e lideranças empresariais comprometidas somente com uma organização. Tratando da formatação financeira dos partidos de massa, observou-se que a militância, os membros do próprio partido e seus simpatizantes são elementos frágeis, insignificantes para a manutenção do financiamento organizacional. Esta realidade foi encontrada em praticamente todos os partidos, com raras exceções. Chama a atenção que esta formatação é encontrada independentemente da coloração ideológica.

O modelo de financiamento tipo catch-all, em que grupos de interesse variados como empresas, sindicatos, associações comerciais são fontes de sustentação das organizações não pode ser desconsiderado. Os dados apresentam a importância deste perfil em alguns partidos, especialmente 
em anos eleitorais cujas legendas estão no governo ou são próximas a ele. $\mathrm{O}$ caso do PT impressiona, pois nele isso fica bem destacado.

No entanto, o que mais salientou na pesquisa foi o predomínio de recursos advindos do fundo partidário. Com poucas exceções, ele foi o principal financiador, apresentando valores muito superiores se comparados com os investimentos das organizações privadas. A questão que nossa pesquisa levanta é se este perfil de financiamento encontrado estaria reforçando a tese da cartelização das organizações partidárias. Ao menos quanto à dimensão do financiamento, os dados indicam que o fundo partidário está produzindo, no caso brasileiro, um efeito que deve ser avaliado com mais atenção.

Em primeiro lugar, se, por um lado, as organizações estão dependentes de um financiamento advindo do Estado, por outro, esse recurso tem se apresentado como elemento essencial para garantir uma desconcentração de recursos que circulam no mercado da oferta partidária. Ou seja, está possibilitando a manutenção de mais atores no jogo da concorrência partidária. Se compararmos o nível de dispersão desses recursos disponíveis com o financiamento das corporações e empresas privadas (pessoa jurídica), as diferenças impressionam (Tabelas 1 e 2). O peso dos recursos privados que fluem nas organizações se concentram em três partidos nos sete anos analisados $\left(2006=91,3 \%, 2007=100 \%{ }^{10}, 2008=81,9 \%, 2009=92,3 \% \%\right.$, $2010=90 \%$ e $2011=97,7 \%, 2012=65,6 \%$ ), e o fundo partidário apresenta maior dispersão, em que três partidos não abocanham percentuais tão altos $(2006=51,7 \%, 2007=48,6 \%, 2008=49,6 \%, 2009=49,9 \%, 2010=49,7 \%$, $2011=50,6 \%, 2012=49,6 \%)$. Em segundo lugar, o financiamento estatal apresenta, para algumas organizações, uma alternativa de contraposição ao domínio financeiro privado, pois, diversificando as fontes de financiamento interno, reduz o desequilíbrio interno diante dos financiadores de empresas privadas.

\footnotetext{
${ }^{10}$ Em 2007, PT e PSDB juntos absorveram todos os recursos de pessoas jurídicas. Em 2011, há um padrão muito diferenciado quanto aos partidos que concentram os recursos financeiros de pessoa jurídica. Durante todo o período analisado, os montantes ficavam concentrados com PT e PSDB; mas neste último ano analisado, o PDT apresentou um perfil destoante. Procuramos saber as razões dessas informações oficiais, mas não encontramos elementos convincentes que esclarecessem os dados.
} 
Tabela 1: Financiamento advindo de fundo partidário, de 2006 a 2009 (em \%)

\begin{tabular}{c|c|c|c|c|c|c|c|c|c|c|c}
\hline & PDT & PSB & PPS & PT & PMDB & PSDB & DEM & PP & PTB & PR & total \\
\hline 2006 & 5,50 & 5,7 & 0,90 & 20,0 & 15,9 & 15,50 & 15,8 & 8,5 & 5,6 & 6,60 & 100 \\
\hline 2007 & 6,40 & 7,2 & 4,50 & 17,6 & 15,3 & 15,70 & 11,6 & 8,5 & 6,7 & 6,50 & 100 \\
\hline 2008 & 6,20 & 7,2 & 4,70 & 17,1 & 16,8 & 15,70 & 12,5 & 8,2 & 5,6 & 6,00 & 100 \\
\hline 2009 & 6,28 & 7,0 & 3,97 & 17,0 & 17,0 & 15,97 & 13,0 & 8,0 & 6,0 & 5,22 & 100 \\
\hline 2010 & 6,18 & 7,0 & 4,73 & 17,0 & 17,0 & 15,75 & 12,0 & 8,0 & 6 & 5,79 & 100 \\
\hline 2011 & 6,30 & 8,6 & 2,40 & 20,5 & 15,8 & 14,30 & 9,2 & 9,1 & 5,3 & 8,50 & 100 \\
\hline 2012 & 6,50 & 9,1 & 2,90 & 19,6 & 16,4 & 13,60 & 8,3 & 9,40 & 5,6 & 8,60 & 100 \\
\hline
\end{tabular}

Fonte: Dados disponíveis em: <http://www.tse.jus.br/partidos/contas-partidarias>.

Tabela 2: Financiamento advindo de pessoa jurídica, de 2006 a 2012 (em \%)

\begin{tabular}{c|c|c|c|c|c|c|c|c|c|c|c}
\hline & PDT & PSB & PPS & PT & PMDB & PSDB & DEM & PP & PTB & PR & Total \\
\hline 2006 & 0 & 4,3 & 0 & 59,8 & 0,7 & 19,30 & 12,2 & 1,40 & 1,9 & 0,4 & 100 \\
\hline 2007 & 0 & 0 & 0 & 74,6 & 0 & 25,40 & 0 & 0 & 0 & 0 & 100 \\
\hline 2008 & 0,20 & 7,6 & 1,50 & 38,6 & 5,8 & 22,30 & 20,8 & 1,60 & 0,9 & 0,7 & 100 \\
\hline 2009 & 0,92 & 0 & 0,61 & 67,0 & 2,0 & 19,30 & 6,0 & 0 & 3,0 & 1,59 & 100 \\
\hline 2010 & 3,50 & 1,0 & 0,18 & 28,0 & 2,0 & 54,00 & 3,0 & 8,0 & 1,0 & 0,10 & 100 \\
\hline 2011 & 71,70 & 2,0 & 0 & 23,0 & 3,0 & 0,05 & 0 & 0,13 & 0 & 0,12 & 100 \\
\hline 2012 & 10,60 & 4,0 & 2,40 & 27,0 & 1,0 & 9,10 & 28,0 & 13,0 & 3,0 & 1,90 & 100 \\
\hline
\end{tabular}

Fonte: Dados disponíveis em: <http://www.tse.jus.br/partidos/contas-partidarias>.

\section{Conclusão}

Este artigo abordou o financiamento partidário brasileiro à luz das principais tipologias partidárias discutidas pela ciência política, a saber: partido de quadros, partido de massa, partido catch-all e partido cartel.

Um breve apanhado da literatura nos forneceu um histórico de como as organizações partidárias foram se moldando ao longo do tempo, e como a constituição de suas fontes de recursos foram se formatando. Nossa intenção, com isso, foi mostrar que o conhecimento dessas fontes de financiamento é importante para melhor identificar a maneira pela qual a organização partidária se relaciona com o Estado e a sociedade. 
Apresentamos os diferentes regramentos sobre o financiamento partidário e as diversas modalidades de que os partidos políticos lançam mão para sustentar suas atividades, como as doações de pessoas jurídicas e físicas, o financiamento com recursos próprios e o fundo partidário.

Para se chegar ao perfil do financiamento dos partidos políticos brasileiros, examinamos os principais deles. E assim, concluímos que modalidades como as doações de pessoas físicas e contribuições de parlamentares mostraram-se insignificantes quando comparadas com a doação de pessoas jurídicas e, principalmente, quando o fundo partidário é considerado. Em geral, o perfil do financiamento indica uma aproximação dos modelos catch-all e cartel.

Nosso estudo aponta para a reflexão de que maior participação estatal no financiamento da vida partidária não leva a efeitos predestinados. Considerando que o modelo do partido cartel é fundamentado em uma relação entre atores (sistema partidário), a projeção de que o fundo público seria um forte limitador e "congelador" da competição do sistema partidário ainda necessita de investigações mais sistemáticas e aprofundadas. As evidências encontradas vão na linha do estudo comparado de Scarrow (2006) feito em países europeus, que chamou a atenção de que subsídios do Estado impactam de forma diferenciada nos sistemas partidários e não necessariamente produzem um processo de cartelização e formação de plutocracias. Um dos argumentos centrais da tese do partido cartel, de que os subsídios são instrumentos criadores de desequilíbrios na competição do sistema partidário parece não ser evidente. Demonstrativos de que a subvenção estatal sufocaria a concorrência não foram encontrados. O que merece uma outra linha de investigação no caso brasileiro é se a subvenção pública impacta o incremento da fragmentação do sistema partidário, evidência encontrada em alguns tipos de regimes de subvenção apresentados no estudo de Scarrow (2006). As recentes fundações e iniciativas de criação de novos partidos no cenário brasileiro também indicam que os subsídios públicos são elementos centrais de incentivo à entrada de novos competidores no mercado ${ }^{11}$. Cabe averiguar de forma mais sistemática os efeitos em questão.

Dado disponível em: <http://acervo.folha.com.br/fsp/2012/06/29/2/>. Acesso em: 12 jan. 2014. Nada menos que cinco partidos foram criados desde 2011. PSD = Partido Social Democrático; PPL = Partido Pátria Livre; PEN = Partido Ecológico Nacional; PROS = Partido Republicano da Ordem Social; SDD = Solidariedade. Dado disponível em: <http://www.tse.jus.br/partidos/partidos-politicos>. Acesso em: 12 jan. 2014. Além do REDE SUSTENTABILIDADE, cuja iniciativa de registro em 2013 não foi aprovada pelo TSE. 
O debate na ciência política sobre o fenômeno da cartelização e subvenção pública ainda precisa amadurecer. Outro estudo recente e que também analisa países europeus, principalmente ex-comunistas, corrobora a tese de que a "entrada" do Estado na vida partidária deve ser avaliada com atenção. A maior regularização e a presença de subsídios na dinâmica da vida dos partidos não apresentaram maior dificuldade de novos atores partidários surgirem no mercado competitivo (Van Biezen e Rashkova, 2011). Mais especificamente em relação aos subsídios estatais, este estudo demonstra um movimento distinto, em que um determinado padrão de competição é mantido, independentemente da entrada do Estado na sustentação das legendas. Ou seja, a introdução de subsídios estatais não necessariamente estimula a ascensão de novos atores e apresenta impactos diferenciados nos sistemas partidários.

No caso brasileiro, há indícios de que o subsídio público esteja contribuindo não somente para garantir a manutenção de atores no jogo competitivo, mas também possibilitando maior competição entre as organizações. $\mathrm{O}$ subsídio estatal parece não estar cartelizando o mercado partidário, mas pelo contrário. Há evidências de estar potencializando uma maior competição que poderia ser completamente amortecida pela influência das corporações privadas. Estas, absorvidas por um reduzido número de partidos, associados ao governo ou com potencial de alternativa de poder.

\section{Referências}

BLYTH, Mark \& KATZ, Richard (2005). "From catch-all politics to cartelization: the political economy of the cartel party". West European Politics, n. 28, p. 33-60.

DUVERGER, Maurice (1970). Os partidos políticos. Rio de Janeiro: Zahar. GUNTHER, Richard \& DIAMOND, Larry (2003). "Species of political parties: a new typology". Party Politics, n. 9, p. 167-99.

KATZ, Richard \& MAIR, Peter (1997). "Party organization, party democracy, and the emergence of the cartel party", em MAIR, Peter. Party system change. Oxford: Clarendon Press Oxford. p. 93-119.

KIRCHHEIMER, Otto (1966). "The transformation of the Western European party systems", em LAPALOMBARA, Joseph \& WEINER, Myron. Political parties and political development. New Jersey, Princeton University Press. p. 177-200. 
KRAUSE, Silvana; DANTAS, Humberto \& MIGUEL, Luis (orgs.) (2010). Coligações partidárias na nova democracia brasileira: perfis e tendências. Rio de Janeiro: Fundação Konrad Adenauer; São Paulo: UNESP.

MAIR, Peter (1994). "Party organizations: from civil society to the State", em MAIR, Peter. How parties organize. Change and adaptation in party organizations in Western democracies. London: Sage. p. 1-21.

(2003). “Os partidos políticos e a democracia”. Análise Social, v. XXXVIII, n. 167, p. 277-93.

MARENCO, André (2001). “Sedimentação de lealdades partidárias no Brasil: tendências e descompassos”. Revista Brasileira de Ciências Sociais, n. 45, p. 69-83.

MARTINS RODRIGUES, Leôncio (2002). Partidos, ideologia e composição social: um estudo das bancadas partidárias na Câmara dos Deputados. São Paulo: EDUSP.

PANEBIANCO, Angelo (2005). Modelos de partido: organização e poder nos partidos políticos. São Paulo: Martins Fontes.

RIBEIRO, Pedro (2009). “Financiamento partidário no Brasil: propondo uma nova agenda de pesquisa". Sociedade e Cultura, n. 12, p. 33-44.

SAFRAN, William (2009). "The catch-all - party revisited. Reflections of a Kirchheimer student”. Party Politics, n. 15, p. 543-54.

SCARROW, Susan E. (2006). "Party subsidies and the freezing of party competition: do cartel mechanisms work?". West European Politics, v. 29, n. 4, p. 619-39.

TAROUCO, Gabriela da Silva \& MADEIRA, Rafael Machado (2013). "Esquerda e direita no sistema partidário brasileiro: análise de conteúdo de documentos programáticos”. Revista Debates, v. 7, n. 2, p. 93-114.

VAN BIEZEN, Ingrid \& KOPECKÝ, Petr (2007). "The State and the parties: public funding, public regulation and rent-seeking in contemporary democracies". Party Politics, n. 13, p. 235-54.

VAN BIEZEN, Ingrid \& RASHKOVA, Ekaterina (2011). "Breaking the cartel: the effect of State regulation on new party entry". Working Paper Series on the Regulation of Political Parties, n. 12, p. 1-29.

WOLINETZ, Steven (2002). "Beyond the catch-all party: approaches to the study of parties and party organization in contemporary democracies", em GUNTHER, Richard; MONTERO, Jose \& LINZ, Juan. Political 
parties. Old concept and new challenges. Oxford: Oxford University Press. p. 136-65.

ZUCCO, Cezar (2011). "Esquerda, direita e governo: a ideologia dos partidos políticos brasileiros”, em POWER, Timothy \& ZUCCO, Cezar. O Congresso por ele mesmo: autopercepções da classe política brasileira. Belo Horizonte: Editora da UFMG.

\title{
Resumo
}

$\mathrm{Na}$ análise sobre partidos políticos há um debate clássico sobre tipologias partidárias. Modelos tipológicos são construídos especialmente a partir de indicadores. O financiamento partidário é uma dimensão central, que oferece parâmetros para a identificação das tipologias. Neste artigo, propomos contrapor os distintos modelos partidários destacados na literatura com os perfis de financiamento encontrados nas organizações partidárias brasileiras. Através de dados do Tribunal Superior Eleitoral (TSE), identificamos a origem dos recursos que financiam as legendas. Concluímos que há um nítido afastamento do caso brasileiro com partidos de quadros e de massa e uma aproximação com um tipo catch-all ou cartel. No entanto, o fundo partidário não tem apresentado elementos que fortalecem a tese de um processo de cartelização. Ao contrário, ele tem contribuído para garantir menor concentração na competição política, bem como manter no mercado maior oferta partidária.

Palavras-chave: Partidos políticos, financiamento partidário, fundo partidário, partido cartel, Brasil.

\begin{abstract}
In analysis about political parties, there is a classical debate about types of parties. Typological models are based specially on indicators. Party funding is a central dimension that provides parameters to identify types. In this paper, we propose contrasting different party models highlighted in literature with the profile of funding found in Brazilian party organizations. Through data provided by the Electoral Supreme Court (TSE), we identify the origin of resources that fund parties. We conclude that there is, in case of Brazil, a clear departure from cadre-based parties of and mass parties and an approximation to a catch-all or cartel party. However, the Party Fund has not shown evidence to support the thesis of a process of cartelization. Instead, it has helped to guarantee smaller concentration in political competition and also to keep a larger supply in the party market.
\end{abstract}

Keywords: Political parties, party funding, Party Fund, cartel party, Brazil.

Recebido em 15 de outubro de 2013.

Aprovado em 29 de janeiro de 2014. 


\section{Erratum - O perfil do financiamento dos partidos brasileiros (2006-2012):}

o que as tipologias dizem?

The profile of political party funding in Brazil (2006-2012): what do typologies say?

No artigo $O$ perfil do financiamento dos partidos brasileiros (20062012): autores, objetivos, êxito e fracasso (1988-2010) e The political reform agenda in Brazil: authors, goals, success and failure (1988-2010) publicado no periódico Revista Brasileira de Ciência Política, número 16, onde se lia:

"O perfil do financiamento dos partidos brasileiros (2006-2012): autores, objetivos, êxito e fracasso (1988-2010)" e "The political reform agenda in Brazil: authors, goals, success and failure (1988-2010)"

leia-se:

"O perfil do financiamento dos partidos brasileiros (2006-2012): o que as tipologias dizem?" e "The profile of political party funding in Brazil (20062012): what do typologies say?". 